\title{
Reflecting on Work Values with Young Unemployed Adults in Finland'
}

I Tuuli Hirvilammi ${ }^{2}$

PhD, Postdoctoral researcher, University of Jyväskylä, Kokkola University Consortium Chydenius, Finland

I Marianne Väyrynen

M.Soc.Sci, University of Jyväskylä, Finland

\section{Ingo Stamm}

PhD, Postdoctoral researcher, University of Jyväskylä, Kokkola University Consortium Chydenius, Finland

I Aila-Leena Matthies

PhD, Professor, University of Jyväskylä, Kokkola University Consortium Chydenius, Finland

I Kati Närhi

PhD, Professor, University of Jyväskylä, Humanities and Social Sciences, Finland

\begin{abstract}
In this article, we explore the internal conversations about the work values of young unemployed adults in Finland. We draw on the theoretical concept of internal conversation by Margaret Archer in order to shift the focus from the individual work values to the interplay between subjective concerns and structural circumstances. The data consist of six group interviews conducted among 29 young unemployed adults. We argue that the internal conversations on work values of young unemployed adults constitute five significant concerns: self-realization and opportunity to contribute to society; sufficient income to live independently; social expectations; challenges of finding employment; and unsustainability of the employment system. These diverse concerns demonstrate that young unemployed adults are constrained agents in a changing context of global environment, Nordic labor market, and activation policies. The results contribute to the explanations for unemployment by emphasizing both the structural factors and reflective agency of young unemployed adults.
\end{abstract}

\section{KEYWORDS}

work values / young adults / unemployment / internal conversation / group interviews

\footnotetext{
${ }^{1}$ You can find this text and its doi at https://tidsskrift.dk/njwls/index.

${ }^{2}$ Corresponding author: Tuuli Hirvilammi, University of Jyväskylä, Kokkola University Consortium Chydenius.E-mail: tuuli.hirvilammi@chydenius.fi.
} 


\section{Introduction}

ordic welfare states face challenges to provide employment for all young adults. Transitions from education to the labor market have become de-standardized, fragmented, and less linear than those experienced by previous generations (Walther 2006). According to Standing (2011), a new precariat class has come to define the more recent generations of young people in particular. Even if there has been a challenge to the view that the precariat is a growing phenomenon (see Pyöriä \& Ojala 2016; Bessant 2018), a recent study by Gallie et al. (2017) demonstrates that insecurities in both job tenure and job status have increased in the 2000s. Structural challenges are also reflected in European employment figures during the 2006-2013 period, and the likelihood of young people facing unemployment is 1.5 times higher than the workforce as a whole (Eurofound 2013; Goffette et al. 2017; O’Higgins 2010).

Alongside growing job insecurity, work has paradoxically become an increasingly pervasive part of our lives. In contemporary western societies, work is connected to identity-building, self-expression, and self-esteem (Fleming 2014). Furthermore, paid work seems to have pervaded all other parts of life, and the distinction between work and leisure time is often blurred. According to Fleming (2014), the increase in the emphasis and importance of paid work is due to the influence of neoliberal economic policies.

In Nordic welfare states, the pairing of neoliberal contraction with an activation paradigm has meant that social security for young unemployed people has partly deteriorated (Lorenzen et al. 2014; Van Aerschot 2011). The reasons for unemployment have become individualized (Van Aerschot 2011). In this context, the unemployed are often labeled as lazy and passive, and are expected to feel guilty if they do not find a work (Fleming 2014; Strangleman \& Warren 2008). For young unemployed adults, the intersection between the structural realities, social expectations, and the individual's capacities might cause fundamental tensions and contradictions (Reiter \& Graig 2005), which are also reflected in work values.

Previous research on work values and work orientation has shown how much young individuals value work (e.g., Bergqvist \& Eriksson 2015; Pyöriä et al. 2017) and what the generational differences are toward work (e.g., Twenge et al. 2010). However, the descriptive quantitative studies omit the focus on the interplay between personal concerns and structural conditions. They have not elaborated on the potential concerns and contradictions related to work values among young unemployed adults nor emphasized the key influence of structural conditions. Also, the significance of weak signals suggesting that some young adults are looking for an alternative lifestyle rather than for paid work (see, e.g., Lähteenmaa 2013) has been overlooked. Even though the awareness of environmental challenges is high among young adults in Finland (Piispa \& Myllyniemi 2019), there is no existing research about the influence of environmental issues on young adults' work values.

In this article, we explore the internal conversations about the work values of young unemployed adults. The aim of the article and its main contribution to the research on work values is to illustrate how the perspective of internal conversation enables a shift in focus from the individual aspects of work values to the interplay between structural circumstances and subjective concerns. We draw on the theoretical concept of internal conversation defined by the social theorist Margaret Archer (2003, p. 8) as a mode of internal but relational dialogue 'through which reflexivity towards self, society and 
the relationship between them is exercised'. Consequently, we approach work values as concerns that individuals reflect in their internal conversations around 'self and society'. This theoretical perspective, combined with the qualitative analysis of group interview data, also enables us to sketch a more diverse picture of contemporary work-related concerns than previous quantitative studies. We argue that studying the shared concerns of unemployed young adults can also contribute to a better understanding of the reasons for unemployment and the possible dilemma young adults face over their personal concerns and structural opportunities.

The article begins with a discussion concerning young adults and work values as a means to laying the foundations for statements used in the group interviews. This is followed by a short overview on the concept of internal conversation, of the methods used, and subsequently the empirical findings and discussion. We conclude by presenting the theoretical contributions of our study.

\section{Young adults and work values}

A common hypothesis in the research on work values and work orientation has been that young adults do not value paid work as much as older generations due to their insecure position in the labor market or their post-materialist values (see Hult \& Svallfors 2002; Hagström \& Gamberale 2003; Pyöriä et al. 2017). However, evidence suggests most young unemployed adults do value work and want to work full-time (e.g., Hult \& Svallfors 2002). In Finland, work orientation has remained stable and is nearly as strong for the young as it is for older generations, despite the increasing value placed on leisure time (Pyöriä et al. 2017). Having paid work is as important to the long-term unemployed, as it is both to young adults in employment and those in a precarious situation both in Finland and in other European countries (e.g., Pyöriä et al. 2017; Bergqvist $\&$ Eriksson 2015). It is therefore likely that unemployed young Finnish adults also wish to work full-time.

The work values of young adults derive from the views and meanings they attach to work. Most frequently, work is simply regarded as a way to earn a living. Jahoda (1982, 83), however, has famously identified five other functions of paid work: it imposes a time structure, expands social networks, offers work status, forms one's personal identity, and forces people to act beyond their personal aims. Work values are shaped by different individual valuations and societal possibilities for meeting these functions. When studying the conceptions of work among urban youth in the USA, Chaves et al. (2004) found that even if young adults had all the finances, they wanted they would still keep working to avoid boredom, to earn more, to benefit others, and to obtain satisfaction from work. Andersson et al. (2017) have found that the most important reasons for working among Swedish young people are 'earning a living and survival' as well as 'self-realization and a good quality of life'. Based on these findings about the various important meanings of work, we can assume that young unemployed adults find work an elementary and important part of life.

When work values are approached in terms of individual orientation, they are understood to be relatively stable and independent of structural conditions. This is evidenced in the categorization of people on the basis of their job, career, and calling orientations (see Shea Van-Fossen \& Vredenburgh 2014). People with job orientation see 
work simply as a job providing financial means, whereas career orientation is found among those who value the rewards attained from work advancement. People with a calling orientation, however, value work for the sense of meaningfulness the work brings them (Domene 2012; Shea Van-Fossen \& Vredenburgh 2014; Sperry 2011). Also, the concepts of intrinsic and extrinsic work goals have been used to explain the differences in personal work values. A person who places a high value on an interesting and responsible job or good social relations expresses intrinsic work goals, whereas a person who values extrinsic work goals appreciates mostly a good salary and a secure job (Gallie et al. 2012; Twenge et al. 2010). Previous research conducted in the 1990s has shown that the importance of intrinsic work goals has increased among young adults due to their post-materialistic values (Hagström \& Gamberale 1995). Due to this focus on intrinsic orientation, we can assume that some young adults in Finland are unemployed because they have not found sufficiently interesting or meaningful work. They might also reflect upon the good balance between a meaningful content of the work and a good salary.

Work values are relational since they are influenced by economic, social, and cultural contexts such as the general work ethic (Davoine \& Méda 2009; Turunen 2014; Wrzesniewski et al. 2003). We therefore suggest that environmental issues might also play a part when young adults reflect upon their work values, especially when knowing that they are the generation that would suffer most if the climate change was not successfully mitigated. In Global Shapers Survey by World Economic Forum (2017), young adults see climate change and destruction of nature as the most serious global issue. In Finland, over half of the young adults are critical toward economic growth and have reduced their consumption for protecting the environment. It seems that young adults are aware how the current employment system is pushing us dangerously against planetary boundaries (e.g., Montt et al. 2018; Räikkönen 2011). Employment is coupled with environmental problems because the increase in production and income levels tend to increase harmful carbon emissions (Gough 2017). Moreover, Nordic employment policies and welfare states are problematically connected to ecologically unsustainable economic growth (Kloo 2015). Based on this critical discussion, working life can be seen as a rat race maintaining a competitive and consumption-oriented lifestyle (e.g., Schor 1999).

\section{Work values from the perspective of internal conversation}

As a critical realist, Margaret Archer (e.g., 2005, p. 201) is 'primarily concerned with relations between people and structures'. She emphasizes the interplay between social structures and human agents and argues that the human power of reflexivity plays a crucial role in mediating between structure and agency. In practice, reflexivity takes place when people perform self-monitoring, self-evaluation, and self-commitment (e.g., Archer 2003).

The concept of internal conversation refers to the final stage of the mediation process by which 'agents reflexively deliberate upon the social circumstances that they confront' (Archer 2003, p. 130). As Archer (2003, p. 13) puts it, a person always subjectively reflects upon herself in relation to the objective conditions. Thus, even though internal conversation is genuinely internal, it is nonetheless a relational dialogue, formulated in the interplay between structure and agency. For Archer (2003, p. 103), internal dialogue is defined as 'the practice through which we "make up our minds" by questioning 
ourselves, clarifying our beliefs and inclinations, diagnosing our situations, deliberating about our concerns and defining our own projects'.

When applying this definition of internal conversation to the analysis of interview data relating to young unemployed adults, we examine how they reflect upon their concerns and define their projects. We thereby see that through internal conversation young adults can modify their life and, as a consequence of internal deliberation, are able to modify the world (see Archer 2003). Inspired by Archer (2000), we approach young unemployed adults as reflexive and evaluative persons who are able to criticize those practices not in line with their own values.

According to Archer, people shape their personal projects based on their ultimate concerns within long-running internal conversations. Conversational processes in which we talk to ourselves are present both in trivial choices and when deciding upon our major commitments (Archer 2003). During the transition phase from adolescence to adulthood, young adults evaluate such major commitments as their values concerning work (Ranta 2013). In addition, personal projects cannot be understood without focusing on reflexive deliberations about concerns connected with the objective social context (Archer 2000). From this perspective, the internal conversation on work values assist in formulating answers to questions such as: What kind of work do I want and why? What does work mean for me? What kind of work is needed in society and what would be my contribution for the common good?

\section{Methods}

We conducted six group interviews with young adults who were participating in activation programs run by public or third sector organizations with a view to mitigating youth unemployment in Finland. These programs aim to improve the employability of young adults at risk of long-term unemployment. Youth Guarantee in Finland, launched in 2013, obliges municipalities to provide a job, work trial, education, or rehabilitation to all young adults under 25 years after a period of three months unemployment (e.g., Kokkonen et al. 2018). The Finnish constitution also guarantees all citizens the right to social protection in case of unemployment. However, due to the activation paradigm and workfare policy in Nordic countries (e.g., Van Aerschot 2011), access to unemployment benefits now involves quite strict conditions. In order to receive benefits, Finnish young adults are required to apply for a place in a school, a job, or to participate in activation programs. If a person refuses to participate, the right to unemployment benefit will be lost and the amount of social assistance can be reduced.

A total of 29 young adults aged between 20 and 29 years were interviewed by the two first authors of the article. ${ }^{1}$ Of the young adults, 11 were male and 18 were female. The participants in the interviews were young adults with a precarious financial situation and semi-financial independence from their family. Some of them had been employed in full-time jobs before, but most of them had very limited experience in part-time, temporary, or seasonal work. The educational background varied from young persons with only an elementary school qualification to persons with vocational professions or studies at university. Most of the interviewees were unmarried, and only one interviewee reported having a child. The majority lived alone and only one participant lived with his parents. 
The number of participants in the groups varied between two and eight persons and the length of the interviews varied between 65 minutes to 2 hours 22 minutes. In total, the interview data contain 132 pages of transcript material.

In cooperation with six different activation programs, we invited young adults to voluntarily participate in group interviews. Since this study is part of a research project with a focus on ecosocial issues (see Matthies et al. 2019), we chose to invite participants from the projects that in some way include environmental perspectives in their practice. For example, one group interview took place in a nature-oriented employment project and one in a social foundation that works in the field of recycling and upcycling. This decision might have increased the presence of environmental concerns in the data.

In addition to open questions, the interview protocol contained 14 statements formulated on the basis of the previous research on youth unemployment, work values, wellbeing, the social security system, and critiques of working culture. In the present article, we analyze the group discussion around the following statements: (1) I am unemployed because I have not found interesting or meaningful work; (2) I do not want to work full-time; (3) work is an elementary and important part of life; (4) the content of the work is more important than a good salary; and (5) working life is a rat race maintaining a competitive and consumption-oriented lifestyle. These statements and open questions were used as a 'discussion stimulus' in the form of a 'provocative thesis' (Flick 2006, p. 195) in order to inspire the participants to reflect on their opinions and in-depth explanations and to provide an opportunity to present critical remarks. We were not only interested in understanding their personal opinions, but we also asked the participants to explain and share their concerns and general insights with others. Consequently, we understand that the comments in the data reflect the internal conversations of the participants while we also acknowledge that the comments are influenced by the external output in group discussions. The statements were used to encourage a lively discussion with diverse arguments and therefore some of the statements were deliberatively formulated in reversed order (such as 'I don't want to work full-time'). We are well aware that some arguments are more socially acceptable than others and that the use of statements introduced by researchers can lead to more biased data. However, during the interviews, we encouraged participants to express their opinions freely and emphasized that the statements were not meant to present correct answers.

In the beginning of the group interviews, handouts printed with the research statements were given to the participants. At first, an interviewer read aloud the statement and asked the participants to openly discuss their ideas on the subject. The other interviewer asked more specific questions when necessary. This structure encouraged spontaneous reactions to fellow participants' comments and systematized the data-collection process. The data are rich with various viewpoints thanks to the group interview method, which is suitable for elaborating on opinions and revealing variations in attitudes. During group interviews, the presence of other participants also modified individual opinions, and discussion developed beyond individual statements. The data therefore consist of a shared elaboration upon the statements rather than definitive and individual statements of single participants (see Frey \& Fontana 1991; Flick 2006). Discussions and arguments also varied greatly between different groups and participants.

We analyzed the group interview data with a thematic analysis method, recommended when studying perceptions and meanings. The purpose of thematic analysis is to find and describe an integrating, relational statement derived from the data. The theme 
identifies both content and meaning. Based on analytic reflection, the analysis aims to find connections and relationships between categories in order to identify their meanings (Bazeley 2013).

In the first stage of the analysis, we read through all the group interview transcripts. Next, we identified 33 data-driven codes, such as 'the meaning of work', 'working time', 'critique towards working life', and 'difficulties in finding a job'. After familiarizing ourselves with the coded material, we paid attention to the diversity of the concerns and to the conflicting issues, such as the emphasis on either meaningful work or good income. Informed by the theoretical concept of internal conversation and the research discussion on work values, we identified five themes that include all major concerns relevant in the data, illustrate the complexity of the issue, and touch upon the structural conditions faced by young unemployed adults. Finally, we coded the interview data once more based on these five themes and analyzed each of them in greater depth.

\section{Results}

In this section, we describe the empirical findings around five themes: self-realization and the opportunity to contribute to society; sufficient income to live independently; social expectations; challenges of finding employment; and unsustainability of the employment system. We argue that these themes describe the concerns of the participants and illustrate well the internal conversations around work values. All these concerns are present when young unemployed adults reflect on their projects and commitments.

\section{Self-realization and the opportunity to contribute to society}

First of all, young unemployed adults express their wish to find meaningful work. They describe eloquently their ideal work and share their aspirations by emphasizing the importance of meaningful work. For instance, one participant describes ideal work as that which 'corresponds to one's own strengths and interests and where you can realize yourself' $\left(1 \mathrm{M}^{2}\right)$.

For many participants, work 'has to be meaningful, it has to give you something' (4 F3). Young unemployed adults want to find purpose in their work and when possible serve the greater good. This is present in the discussions where participants take distance from their parents' generation and highlight the connection between ideal work and psychological wellbeing:

- But really, work has to be such that it is meaningful, that you have something meaningful to do. And this is maybe also the issue where young adults are often accused of thinking that everything should be fun, and they are reminded that life is not only about having fun and being easy. But I don't think that's the question. If you have been doing a job for 40 years and it causes anxiety, I don't think life is necessarily worth living. One is then allowed to look for something that's meaningful. (6 F4)

Participants acknowledge that finding meaningful work is an ideal that may not always be possible. The data contain many sentences starting with 'but', which reflects the signs 
of young adults' inner tensions and their constrained agency: they recognize idealistic plans but are well-aware of their limitations in real life. One young adult expressed this constrained agency, for instance, by describing her plans as 'career A and career B': 'A' being meaningful and creative work, and ' $\mathrm{B}$ ' 'the more rational choice' (4 F2). A similar tension is present when participants talk about various motives and link them both to the call for self-realization and concerns to earn money, as is seen in this dialogue extract:

- So somehow like what you said, that you know yourself and what you do, you give your own contribution, and through that you get something and feel like a significant person. (4 F3)

- The other thing is like when you are a carpenter, it is creative work, you leave behind your handiwork in a totally different way than if you just do the dishes; the mountain of dishes never ends, and you always have the same. Every day you do the same thing as the previous day. It's always repeating the same work. I once had such a repetitive type of job. Some parts of it were nice, but others were very boring. (4 F2)

- On the other hand, that kind of work can be motivated by money, which is a necessary evil anyway ... that there is some motivation. (4 F1)

- But in the end that will not last very long. (4 F2)

- Yes, true. (4 F1)

- You can keep doing anything if there is a good salary, but then at some point you get bored if there is nothing else. (4 F2)

In this group interview discussion, the participants refer to the intrinsic and extrinsic work goals and recognize the limits of the latter. They consider creative artistic work less constrictive and more rewarding than repetitive types of work important mainly for earning money.

The emphasis on meaningful work is seen in the comments where the participants would be ready to work long hours even if it blurred the line between work and leisure time. They are also ready to trade income for a meaningful job. Sometimes the commitment to meaningful and valuable work can be stronger than to a paid position: 'So I want to feel that I am doing something for subsistence or for having a meaningful life regardless of whether it is paid or not' (1 F3). Some participants have already chosen not to work in repetitive jobs because it took too much energy and did not allow possibilities for self-realization.

Young unemployed adults understand how they could be seen as 'picky about work' (6 F1) if they are not ready to accept all kinds of work. However, the goal to find meaningful work is not only discussed as a selfish desire to follow individual interests. Rather, it is also explained in terms of social responsibility and contribution. This can be seen, for example, in the following statement: 'The ideal in working life is that there would be some kind of bigger aim or goal, and that it would be beneficial not only for myself but for others as well' (4 F3).

Social contribution is considered important because it would offer meaning and improve one's social position in society: '[I would have some feeling] that I am a meaningful person in society and that what I do has some importance, so that I am needed' (6 F4). Examples of concrete contributions that correspond to the interests of the participants include helping the poor, enhancing welfare, doing care work, rescuing animals, 
protecting the environment, developing production based on recycled material, and engaging in activism. Interestingly, many of these interests the young adults mentioned would also enhance social and ecological sustainability and thus contribute to the wider transition toward a sustainable future.

\section{Sufficient income to live independently}

An important concern related to work values is the need for a sufficient income. Earning money is considered to be a rational choice and an obligation: 'it's certainly nice, if one gets a salary. Though it's important that the work is meaningful, in the end you have to make your living somehow' (3 F2). The citation reflects the order of the importance when the participant first explains how she prefers meaningful work but then admits that, in the end, a salary is more urgent. It might be a wise choice to give up on overly idealistic work aspirations and to accept the priority of paid employment. When asked to clarify further about what would be the rational choice, one participant answered: 'the sensible thing would be to have the kind of profession where you can earn an income that is paid regularly and that is so-called safe work or a safe career' (4 F1).

The discussion on work values also includes statements that reflect the importance of the extrinsic rewards of work, such as good pay and material possessions. Even though most of the participants agree that the content of the work is more important than the salary, they value earnings in order to save money for the future. When taking part in activation programs, the young unemployed adults earn around $€ 10$ more per day than they would on the minimum level of unemployment benefit and social assistance (around $€ 480-650$ per month). Consequently, all participants were at risk of poverty (income below $60 \%$ of the median income) and faced the impacts of relative poverty. They lack the opportunities to follow the widely shared consumption possibilities within Finnish society, which might increase their desire to find a well-paid job. This is clearly expressed by one participant: 'I have always been greedy for money since I have always had to count every penny. So, if I was able to have a good salary from some lousy job, I would just be happy' (5 F1). Due to the poverty and insecurities in income they have already faced, some young unemployed adults express strong aspirations toward traditionally safe and permanent working contracts.

Young Finnish adults typically move from their childhood home relatively early compared to other European countries (Ranta 2013). Against this background, it is understandable that the interviewees also feel embarrassed when they were forced to borrow money from their family members. Thus, earning their own money from a paid job would make them more independent. When unemployed, the participants are also financially dependent on different social benefits, such as unemployment benefits, housing benefits, and means-tested social assistance. Many interviewees oppose this dependency and want to be employed; to be more self-sufficient by earning their own money. Consequently, one issue related to work values is the uneasy feeling when living on benefits, as one participant expressed: 'I would like to earn some money, even save something. I feel self-conscious that I receive benefits. But it is not earned, so it would be nice to do something for work' (2 M3). To many, social security does not feel like real earnings and honestly deserved money. Some of the participants express clearly how ashamed they feel when living on welfare, which can be explained by the social expectations they face. 


\section{Social expectations}

The social norm to work is conspicuously present in the internal conversations of young unemployed adults. When reflecting on their opportunities for the future and concerns about unemployment, the participants discuss how they face expectations from outside to be a productive, paid worker. The expectations are felt on many occasions and also within families, which implies something about the high work ethic in Finnish society. Knowing this, some participants describe their mixed feelings when they are without work: 'I come from that kind of family where there is some kind of pride in those things. So it hurts my self-esteem when I don't have a job' (2 M3).

Unemployed young adults do not celebrate joblessness but rather are a little ashamed of it. The lower social status they feel becomes obvious in the following citation from one group discussion, in which the participants start to discuss what would change if they found employment:

- Then the status will change automatically. You anyway feel too much like a lower person. (1M3)

- Oh, what do you mean ... that the others are thinking? (interviewer 2)

- At least I started to feel so when I spent one year in [a small municipality in Finland] without doing anything, on so-called sick leave. So, in principle I didn't have any value. Well, that's how I felt in front of the neighbors and I noticed it when I moved to [another small municipality] to a one-family house with its own garden. Then it felt like I was some kind of master there and the neighbors looked differently. In the previous place they stared at me, when they knew it was the only apartment owned by the social services. I noticed that, or then I imagined. But I don't know.

- At least you don't feel like you're some kind of spittoon when you do something valuable. (1F2)

- Exactly. And that you can be useful at least somewhere so that you are not just a dishcloth at home. (1F1)

The lower social status felt by unemployed people is expressed clearly when the participants describe themselves with metaphors like 'spittoon' and 'dishcloth' - items that have remarkably low value. The statements reflect the aspiration that paid work would significantly improve the participants' social position.

The social pressure to find a job also comes from the public discourse. Young adults are aware that unemployed people are often labeled as passive and lazy: 'In the public discussion the blame is somehow put on us; like why are young people just laying around at home doing nothing and not actively seeking work and so on ...' (6 M4). Similar labeling is experienced within the social services when participants try to find support but end up feeling that the practitioners in the services have prejudices and hostile attitudes towards them.

Young unemployed adults criticize the job center, in particular, for being 'a whipping system' (4 F2), which forces them to take part in activation courses and unpaid work placements. They emphasize their aspirations to autonomously choose the work that is suitable for them and corresponds to their values, rather than being available for any kind of paid job. It was felt that the job center and social workers do not always understand these aspirations:

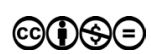


- They call from their ivory tower saying that you just need to work, but of course people have their own limits in regard to what work they are willing to do. Like I don't want to work in telemarketing because I'm not a person who can just harp on about the same thing. It's not for me. So I want to decline such work because I know that it's unsuitable for me and would therefore make my life worse. (3 F4)

- And at worst it can affect your work ability as well ... (3 F6)

The authorities are regarded as being distant in their 'ivory tower' and as not respecting the wishes of young unemployed adults. In the above passage, the participant strongly disagrees with social expectations, and emphasizes the freedom to decline unsuitable work. The desire to retain such agency was strong. Even though the activation paradigm has made social security stricter and more conditional in Nordic welfare states, the reality is that young unemployed adults in Finland can receive a reduced level of minimum income if they choose not to work.

\section{Challenges of finding employment}

The group interviews with the young unemployed adults also reflect their concerns in relation to the challenges of finding employment. While being unemployed, they have had to confront the lack of jobs: 'One thing is that they don't employ. You can find unpaid work placements, but once finished they don't need you anymore' (2 M3). Or, as another participant bitterly states: 'there are no jobs in my field' (5 F1). Educated young adults in particular feel frustrated and betrayed if the only job opportunities are those they could do without any formal education: 'I have three professions, and still I can't seem to find a job anywhere. I could start cleaning some goddam toilets if I wanted to. But I'm not so interested' (1 F1). Here, the young participant has suffered from the lack of professional jobs but, nevertheless, refuses to give up her plans for a professional career.

Whereas the public discourse and actors within public policy often try to attach the reasons for youth unemployment to the young adults themselves, the participants raise their concerns about the structural problems that shape the situation. The reasons for being unemployed are explicitly linked to the challenging situation in the labor market rather than with the lack of individual capacities, or will:

- Actually, all unemployed people who I know and who have been unemployed for a longer time are unemployed for reasons other than their laziness or disregard or anything like that. They either have some need for rehabilitation, or they simply don't get a job regardless of their repeated efforts to find one. (4 F2)

- Yes, if you have training in a field like media with only a few jobs available, or some art field where there is a lot of work but few employers or grants, so there are also lots of structural problems. (4 F1)

This group discussion around the challenges of finding employment shows how the participants have adopted or even internalized the public discourse as part of their internal conversation. In order to distance themselves from public discourse, the participant needs to emphasize the reasons other than 'laziness' or low interest in employment. It 
is acknowledged that some young people are unemployed not only because of the challenges to find a job but also due to other acceptable reasons such as health problems or a reduced ability to work. In the end, the concern related to the challenges to get employed most obviously highlights the question of the interplay between subjective aspirations and objective reality. It can be highly frustrating, and can limit the agency of the participants, if they do not find a job in spite of all their efforts. When pondering upon working possibilities, the young unemployed adults are ultimately dependent on the basic structural issue of job availability.

\section{Unsustainability of the employment system}

The final concern around work values touches upon the unsustainability of the present employment system, from the perspective of both ecological and social sustainability. In contrast to the activation paradigm within Nordic countries, which regards all jobs as valuable and employment always as the main goal without questioning the sustainability of the system, many young unemployed adults do see problems with the present employment system. Some of the interviewees criticize the negative health effects of work. One participant, for example, wants to avoid working in the chemical industry like his father because he sees it as bad for one's health.

Many participants criticize the overall emphasis on increasing productivity and believe that the current labor market demands too much from workers:

- Of course there are some jobs like telemarketing jobs [available], but I don't see such work as being good for anyone because you just have to be super-productive all the time. It doesn't matter if you are really able to do the job, you simply have to make a profit for that company so that they pay your salary. Even though you work so much they are never satisfied, so it's not at all healthy. (3 F3)

In the group discussions, some participants reflect the broader context of working life by accusing the economic system in general and stressing that they do not want to work for people who are already rich and will gain even more from their contribution. For example, one participant argues that 'people are like some kind of consumer goods for companies; they just whip the maximum out of the workers' (4 F2). Due to these presumed expectations, some interviewees question whether they could work fulltime at all and be as productive as needed. This is why they would sometimes prefer to work part-time, which they believe is more in line with their own physical and mental abilities.

The tendency toward maximal profit-making and high performance in the labor market is also seen as problematic for the natural environment. When discussing the statement concerning the rat race and a consumption-oriented lifestyle, many participants often spontaneously began to express their worries about environmental problems. The worries are expressed, for example, in the following statement of one participant: 'If we rape all the land and cut down all the trees, we will soon have very high carbon emissions. Then slowly everything gets worse; it's going to come back and bite us if we ruin those things' (4 F2).

The participants in three group discussions were more critical and aware of the sustainability challenges than in other groups. They did not only blame the employment system 
for the environmental problems but also broadly discussed the challenges of an unsustainable growth-oriented economy. As this dialogue extract from one discussion shows, the young participants also show awareness of the major problems of consumer culture and are concerned with the overall emphasis on the economic side in the labor market:

- Yes, all forests are cut down to make way for [...] new shopping centers. (1 F3)

- I think the problem relates to the fact that you always have to think or want to think about the economical side. And often it is cheaper to destroy and build new rather than recycle and fix the old ones. I think it should be vice versa, that it should always be cheaper to [...] use the old ones than produce new ones. But for some reason the economy has developed in such a way that destroying is always cheaper. (1 F5)

- And then this maximizing consumption, like the scam with light bulbs that they break after a certain time of use and we are forced to consume ever more even though we don't want [...]. (1 F1)

- But it's not necessarily the fault of the companies or the labor market that it's like this. But also in the labor market one has to think about the economical side and it's a little sad. (1 F5)

It seems that the concerns about the unsustainable system are not irrelevant for young unemployed adults when they reflect on their work values and make plans for the future. Some of the interviewees express having a bad conscience when they are put in a situation where they have to work against their own values. The commitments that are part of the personal projects of the participants are present in these two separate quotations:

- For instance, if I would be able to earn loads of money but to do so would have to work by lobbying for some oil company, then no, I wouldn't do it. It would go so much against my own principles. (3 F 1 )

(一)

- I am educated in forestry, but I would not agree to operate forest machinery and make big clearings in woods or do something clearly harmful to the nature, or environmentally harmful work. So I couldn't do that, at least not for too long. I would not be able to sleep at nights because I am so sensitive. (3 M7)

These kinds of critical remarks and ethical considerations can explain why some young adults would prefer to wait for meaningful work and stay unemployed rather than applying for available job vacancies that are regarded as unsustainable. The discussion about the concerns around unsustainability shows how young unemployed adults' internal conversation about work values also touches upon ethical commitments and moral issues.

\section{Discussion}

The internal conversation of young unemployed adults around their work values constitutes five significant concerns: (1) self-realization and the opportunity to contribute to society, (2) sufficient income to live independently, (3) social expectations, (4) challenges of finding employment, and (5) unsustainability of the employment system. The five 
concerns and their interconnections become visible when imaging a young adult who reflects upon her working opportunities after education. First, she wants to recognize what would be her 'calling' and her possible contribution to the common good. At the same time, she is aware of the realities of the labor market, which makes it challenging or even impossible to find a job that is both meaningful and offers a decent income. She also faces social pressure to support herself financially. Further, when planning her future, she reflects on the broader context of the employment system and such troublesome questions as: Is this system socially and ecologically sustainable and how do I want to be involved in it? These concerns illustrate the interplay between subjective and objective reality that influences the work values of young adults.

Consistent with the results of Bergqvist and Eriksson (2015) and Andersson et al. (2017), the participants in this study seem to appreciate work for many reasons: it provides meaningful activities, social status, and personal development. When work is attached to a sense of self, it comes close to the 'calling' orientation, identity building, and self-expression (see Chalofsky 2003; Fleming 2014). As Bailey and Madden (2017, 4) have suggested, meaningfulness in work refers to experiences of 'existential significance' and 'purpose of life', and thus to the commitments and personal projects that are modified through an internal conversation. Young participants value meaningful work that is in line with their ultimate concerns (Archer 2003) and with their identity. The discussion about self-realization demonstrates those subjective commitments that young unemployed adults would prefer to follow if they did not need to consider any structural constraints. However, the commitments are not merely selfish when the young unemployed adults emphasize the contribution to the common good. This also becomes visible in their considerations of the reasons to work and in their reflections on the broader contribution of ones' own agency.

Work is also valued according to the income it would provide. Following the previous studies, the interviewees are motivated by the extrinsic rewards of work such as good pay and material possessions (e.g., Andersson et al. 2017; Twenge et al. 2010). Some of the participants expressed more of a job-orientation, being more willing to work simply with a view to earning money, while others expressed more of a callingorientation by talking more about the importance of self-realization (see Sperry 2011). However, from the perspective of internal conversation, it makes no sense to classify individuals according to their orientations. Rather, we argue that young adults might share all orientations, be it calling, job, or career, but these more subjective orientations are expressed depending on the objective opportunities they have.

Internal conversations on work values depict the voices from 'outside', namely social norms and expectations. The concerns about social expectations reflect the importance of the interplay between 'self and society' (see Archer 2003, 8). Along with Wrzesniewski et al. $(2003,128)$, we see how work values are linked with 'interrelational dynamics' and are always related to social reality. For example, in the Finnish context where young adults generally have a high work-orientation (e.g., Pyöriä et al. 2017), the participants do not celebrate joblessness but are in fact somewhat ashamed of it (see also Strangleman \& Warren 2008; Jahoda 1982). The social pressure to be a productive employee also derives from activation policies and public authorities, the attitudes of which can be negative and discouraging. Young unemployed adults in Nordic welfare states experience more means-tested unemployment benefits (Lorenzen et al. 2014) and activation programs than older generations. As Lähteenmaa $(2013,80)$ has argued, Finnish 
authorities expect young unemployed adults to know their 'duty to work'. However, the young participants tended to raise the question of the extent to which they can give up their own interests and commitments in favor of this sense of obligation and social expectations. We interpret the discussion on the limits of work as reflections of an internal conversation where a person seeks a balance between concerns for self-realization, social expectations, and structural problems.

The connection between work values and the challenges faced in the labor market has not been considered a great deal in previous studies, though they are clearly related. The studies focusing on individual attitudes seem to assume - at least implicitly - that commitment to work is quite stable and not in fact decreasing due to the challenging labor market situation (see, e.g., Hagström \& Gamberale 1995; Twenge et al. 2010). We argue, however, that the awareness and experiences of the challenges of finding a job do play a role when young adults reflect upon their work values.

The findings bring to light the environmental concerns of young participants and critical remarks on the employment system, all of which is novel in the existing research on work values. However, more research is needed to study the impacts of these critical remarks in Nordic welfare states. Pyöriä et al. (2017) have argued that the young generation in Finland will not push working society toward any radical changes because their attitudes to work are more conservative than radical. Nevertheless, we also found some less conservative ideas and more critical statements on the structural conditions. It remains to be seen whether these 'agents', young adults, will 'in turn react back to reproduce or transform structure' (Archer 1998, 371) toward more sustainable work (see Montt et al. 2018).

\section{Conclusion}

In this article, we articulated a theoretical approach toward internal conversation and employed it within the empirical analysis of the work values of young unemployed adults. Our goal was to contribute to the research on work values by illustrating how the perspective of internal conversation enables a shift in research focus from individual attitudes to the interplay between structure and agency. The focus on the internal conversations of young unemployed adults helps position them as constrained agents within the changing context of global environment, labor market, social security, and activation programs. The key findings contribute to the explanations for unemployment by emphasizing both the structural factors and reflective agency of young unemployed adults. Work values are structurally embedded, thus revealing a need for structural level policy solutions in order to mitigate youth unemployment in Nordic welfare states.

\section{References}

Andersson, M. \& Gunnarsson, K. \& Hedlund, A. \& Rosén, G. (2017). Young people's attitudes to attractive work, during and after upper secondary school, Nordic Journal of Working Life Studies 7(1): 55-68. Doi: https://doi.org/10.18291/njwls.v7i1.81399.

Archer, M. S. (1998). Realism and morphogenesis. In Archer, M, Bhaskar, R., Collier, A., Lawson, T. \& Norrie, A. (Eds.). Critical Realism. Essential readings, London: Routledge: 356-381. 
Archer, M. S. (2000). Being Human. The Problem of Agency, Cambridge: Cambridge University Press.

Archer, M. S. (2003). Structure, Agency and the Internal Conversation, Cambridge: Cambridge University Press.

Archer, M. S. (2005). Critical Realism and Relational Sociology, Journal of Critical Realism 9(2): 199-207. Doi: https://doi.org/10.1558/jcr.v9i2.199.

Bailey, C. \& Madden, A. (2017). Time reclaimed: temporality and the experience of meaningful work, Work, Employment and Society 31(1): 3-18. Doi: https://doi. org/10.1177/0950017015604100.

Bazeley, P. (2013). Qualitative Data Analysis. Practical Strategies, London: Sage.

Bergqvist, T. \& Eriksson, B. (2015). Passion and exploitation among young adults with different labor market status in Europe, Nordic Journal of Working Life Studies 5(2): 17-31. https://doi.org/10.19154/njwls.v5i2.4791.

Bessant, J. (2018). Young precariat and a new work order? A case for historical sociology, Journal of Youth Studies, 1-19. Doi: https://doi.org/10.1080/13676261.2017.1420762.

Chalofsky, N. (2003). An emerging construct for meaningful work, Human Resource Development International 6(1): 69-83. Doi: https://doi.org/10.1080/1367886022000016785.

Chaves, A. \& Diemer, M. \& Blustein, D. \& Gallagher, L. \& DeVoy, J. \& Casares, M. \& Perry, J. (2004). Conceptions of work: the view from urban youth, Journal of Counseling Psychology 51(3): 275-286. Doi: https://doi.org/10.1037/0022-0167.51.3.275.

Davoine, L. \& Méda, D. (2009). Work more to earn more: the mixed feelings of Europeans, International Labor Review 148(1-2): 15-46. Doi: https://doi.org/10.1111/j.1564913x.2009.00047.x.

Domene, J. F. (2012). Calling and career outcome expectations: the mediating role of self-efficacy. Journal of Career Assessment 20(3): 281-292. Doi: https://doi.org/10. $1177 / 1069072711434413$.

Eurofound (2013). Working Conditions of Young Entrants to the Labor Market, Dublin: European Foundation for the Improvement of Living and Working Conditions.

Fleming, P. (2014). Resisting Work. The Corporatization of Life and Its Discontents, Philadelphia: Temple University Press.

Flick, U. (2006). An Introduction to Qualitative Research, London: SAGE.

Frey, J. \& Fontana, A. (1991). The group interview in social research, The Social Science Journal 28(2): 175-187. Doi: https://doi.org/10.1016/0362-3319(91)90003-m.

Gallie, D. \& Felstead,A. \& Green, F. \& Inanc, H. (2017). The hidden face of job insecurity, Work, Employment and Society 31(1): 36-53. Doi: https://doi.org/10.1177/0950017015624399.

Gallie, D., Felstead, A. \& Green, F. (2012). Job preferences and the intrinsic quality of work: the changing attitudes of British employees 1992-2006, Work, Employment and Society 26(5): 806-821. Doi: https://doi.org/10.1177/0950017012451633.

Global Shapers Survey. (2017). World Economic Forum. Available at: http://www.shaperssurvey2017.org/static/data/WEF GSC Annual Survey 2017.pdf.

Goffette, C., Vero, J., Graham, H., Raeside, R., Chiappero-Martinetti, E., Spreafico, A. M. C. \& Peruzzi, A. (2017). The participation of the young in the European Union. In Otto, H.-U., Egdell, V., Bonvin, J-M., \& Atzmüller, R. (eds.) Empowering Young People in Disempowering Times. Fighting Inequality Through Capability Oriented Policy, Cheltenham \& Northampton: Edward Elgar: 39-53.

Gough, I. (2017). Heat, Greed and Human Need. Climate Change, Capitalism and Sustainable Wellbeing, Cheltenham: Edward Elgar.

Hagström, T. \& Gamberale, F. (1995). Young people's work motivation and value orientation, Journal of Adolescence 18(4): 475-490. Doi: https://doi.org/10.1006/jado.1995.1034.

Hult, C. \& Svallfors, S. (2002). Production regimes and work orientations: a comparison of six western countries, European Sociological Review 18(3): 315-331. 
Jahoda, M. (1982). Employment and Unemployment. A Social-Psychological Analysis, Cambridge: Cambridge University Press. https://doi.org/10.1093/esr/18.3.315.

Kloo, D. E. (2015). The sustainability of welfare capitalism. Redefining institutions and agency. In Borgnäs, K., Eskelinen, T., Perkiö, J. \& Warlenius, R. (eds.) The Politics of Ecosocialism: Transforming Welfare, London and New York: Routledge, 34-52.

Kokkonen, T., Närhi, K. \& Matthies, A-L. (2018). Active citizenship and participation as transformation of the Finnish welfare state. In Kamali, M. \& Jönsson, J. H. (Eds.) Neoliberalism and Social Work in Scandinavian Welfare States, Oxford: Routledge, $35-45$.

Lorentzen, T., Angelin, A., Dahl, E., Kauppinen, T., Moisio, P., \& Salonen, T. (2014). Unemployment and economic security for young adults in Finland, Norway and Sweden: from unemployment protection to poverty relief, International Journal of Social Welfare 23(1): $41-51$.

Lähteenmaa, J. (2013). Agency vs. structure: a view of youth unemployment during the current recession in Finland. In Helve, H. \& Evans, K. (eds.) Youth and Work Transitions in Changing Social Landscapes, London: Tufnell, 68-81.

Matthies, A. L., Stamm, I., Hirvilammi, T., \& Närhi, K. (2019). Ecosocial innovations and their capacity to integrate ecological, economic and social sustainability transition, Sustainability 11(7): 2107. Doi: https://doi.org/10.3390/su11072107.

Montt, G., Fraga, F. \& Harsdorff, M. (2018). The Future of Work in a Changing Natural Environment: Climate Change, Degradation and Sustainability. ILO Research Paper Series, Geneva: International Labour Office.

Piispa, M. \& Myllyniemi, S. (2019). Youth and climate change. Knowledge, concerns and action in light of youth barometers. [Nuoret ja ilmastonmuutos. Tiedot, huoli ja toiminta Nuorisobarometrien valossa.] Yhteiskuntapolitiikka 84:1, 61-69.

Pyöriä, P. \& Ojala, S. (2016). Precarious work and intrinsic job quality: evidence from Finland, 1984-2013, The Economic and Labor Relations Review 27(3): 349-367. Doi: https://doi.org/10.1177/1035304616659190.

Pyöriä, P., Ojala, S., Saari, T. \& Järvinen, K. (2017). The millennial generation: a new breed of labor? SAGE Open 7(1). Doi: https://doi.org/10.1177/2158244017697158.

Ranta, M. (2013). Finnish young adults' financial well-being in times of uncertainty. In Helve, H. \& Evans, K. (eds.) Youth and Work Transitions in Changing Social Landscapes, London: Tufnell, 58-67.

Reiter, G. \& Craig, G. (2005). Youth in the labor market: citizenship or exclusion? In Bradley, H. \& van Hoof, J. J. (eds.) Young People in Europe: Labor Markets and Citizenship, Bristol: Policy Press, 15-39.

Räikkönen, T. (2011). The greening of work: how green is green enough? Nordic Journal of Working Life Studies 1(1): 1-17. Doi: https://doi.org/10.19154/njwls.v1i1.2338.

Schor, J. B. (1999). The Overspent American: Why we Want What we Don't Need, New York: Harper Perennial.

Shea-Van Fossen, R. \& Vredenburgh, D. (2014). Exploring differences in work's meaning: an investigation of individual attributes associated with work orientations, Journal of Behavioral and Applied Management 15(2): 101-120.

Sperry, L. (2011). The challenge of work: the influences of work orientation and stage of expertise on social interest, Journal of Individual Psychology 67(2): 162-171.

Standing, G. (2011). Precariat. The New Dangerous Class, London: Bloomsbury Academic.

Strangleman, T. \& Warren, T. (2008) Work and Society. Sociological Approaches, Themes and Methods, London and New York: Routledge.

Turunen, T. (2014). Lack of commitment? Work orientations of Finnish employees in a European Comparison, Nordic Journal of Working Life Studies 4(2): 65-83. Doi: https://doi. org/10.19154/njwls.v4i2.3865. 
Twenge, J., Campbell, S. Hoffman, B. \& Lance, C. (2010) Generational differences in work values: leisure and extrinsic values increasing, social and intrinsic values decreasing, Journal of Management 36(5): 1117-1142. Doi: https://doi.org/10.1177/0149206309352246.

Van Aerschot, P. (2011) Activation Policies and the Protection of Individual Rights. A Critical Assessment of the Situation in Denmark, Finland and Sweden, Burlington: Ashgate.

Walther, A. (2006) Regimes of youth transitions: choice, flexibility and security in young people's experiences across different European contexts, Young 14 (2): 119-139. https:// doi.org/10.1177/1103308806062737.

\section{Notes}

${ }^{1}$ The interviews were conducted in Finnish except with the one participant who answered in her mother tongue, Swedish. The quotations in this article have been translated by the authors, who are fluent in all three languages.

${ }^{2}$ The first number indicates the number of group interviews, the letters $\mathrm{F}$ and $\mathrm{M}$ indicate the gender, and the last number indicates the participant of each group interview. 